\title{
DIRETRIZES CURRICULARES PARA 0 CURSO DE PEDAGOGIA - UM PERCURSO HISTÓRICO E DE REFLEXÕES NA UNICENTRO
}

\author{
CURRICULAR LINES OF DIRECTION FOR THE COURSE OF PEDAGOGIA - A \\ HISTORICAL PASSAGE AND REFLECTIONS IN THE UNICENTRO
}

\section{DIRECTRIZES CURRICULARES PARA EL CURSO DE PEDAGOGÍA - UNA TRAYECTORIA HISTÓRICA Y DE REFLEXIONES EN UNICENTRO}

Margareth Fátima Maciel ${ }^{\star}$

Clarice Schneider Linhares

\begin{abstract}
Resumo: O texto apresenta o processo de implantação das diretrizes curriculares do curso de Pedagogia da UNICENTRO, abordando um histórico do curso desde a sua criação, em 1977, passando pelas leis nacionais que influenciaram as mudanças no seu Projeto Político Pedagógico até os dias atuais. A análise é feita a partir dos documentos existentes no Departamento de Pedagogia, na literatura que trata das leis nacionais da educação e das experiências vivenciadas pelos docentes durante a organização e discussão do processo atual.
\end{abstract}

Palavras-chave: Diretrizes curriculares. Pedagogia. Projeto pedagógico. Formação de professores.

\begin{abstract}
The text presents the process of implantation of the curricular lines of direction of the course of Pedagogia of the UNICENTRO, approaching a description of the course since its creation, in 1977, passing for the national laws that had influenced the changes in its Project Pedagogical Politician until the current days. The analysis is made from existing documents in the Department of Pedagogia, in the literature that deals with the national laws of the education and the experiences lived deeply for the professors during the organization and quarrel of the current process.
\end{abstract}

Key-words: Curricular lines of direction. Pedagogia. Pedagogical project. Formation of teachears.

Resumen: El texto presenta el proceso de implantación de las directrices curriculares del curso de Pedagogía de UNICENTRO, abordando un histórico del curso desde su creación, en 1977, pasando por las leyes nacionales que influenciaron los cambios en su Proyecto Político Pedagógico hasta los días actuales. El análisis es hecho a partir de los documentos existentes en el Departamento de Pedagogía, en la literatura que trata de las leyes nacionales de la educación y de las experiencias vivenciadas por los docentes durante la organización y discusión del proceso actual.

Palabras-clave: Directrices curriculares. Pedagogía. Proyecto pedagógico. Formación de profesores.

\footnotetext{
${ }^{*}$ Doutora em Educação: Currículo pela PUC-SP. Professora da Universidade Estadual do Centro Oeste. Email: margamaciell@gmail.com

** Doutora em Educação pela Universidade Tuiuti do Paraná. Professora da Universidade Estadual do Centro Oeste. Email clarinhalinhares@yahoo.com.br
} 


\section{Introdução}

Escrever não é tarefa fácil, sobretudo quando se trata de atender um convite inesperado e, também, muito provocador. Mas na tentativa de trazer algo novo e descobrir, ao mesmo tempo, a novidade escrevendo, emprego aqui as palavras mais particulares e abertas para fazer sentido o motivo que as despertou. Particulares, pois representam minha análise sobre o tema e, abertas para que possam receber toda contribuição e ampliar as discussões ora apresentadas.

Escrever sobre o curso de Pedagogia na Universidade Estadual do Centro Oeste - UNICENTRO e a construção de suas concepções e perspectivas, constituem em um desafio para quem está iniciando um novo olhar sobre a formação de professores, a partir das mudanças nos sistemas produtivos decorrentes dos enormes avanços técnicos dos processos de informatização e de comunicação na sociedade.

Entendendo que a Universidade tem um papel significativo na sociedade e, para que esse papel possa garantir a qualidade na educação, pressupõe-se o desenvolvimento permanente de alguns aspectos fundamentais que constituem os objetivos da Instituição como o seu projeto pedagógico e dos cursos que possui, os recursos humanos e a infra-estrutura, bem como o gerenciamento adequado de todos os setores. De um lado, estes aspectos estão inter-relacionados às propostas e direcionamentos técnico-científicos e, de outro, são acompanhados por todo um conjunto de mudanças que incidem sobre $o$ mundo do trabalho sujeito, hoje, aos fatores relacionados a organização da produção e ao desenvolvimento tecnológico.

Neste contexto se insere o curso de Pedagogia como o espaço específico na Universidade para a realização de estudos e discussões sobre as questões educacionais e, também responsável pela formação de professores nas diversas áreas do conhecimento em que, a influência da tecnologia parece estar presente de forma muito incipiente e indireta ainda.

Desejando pensar de um jeito claro e objetivo sobre isso, e tendo um quadro teórico composto pela cultura tecnológica e pelo ensino institucionalizado, sigo na tentativa de encontrar uma realidade sinalizada por uma ponta de esperança daqueles que acreditam que há sempre dimensões novas a serem reveladas no dia-a-dia aparentemente linear da educação.

\section{O curso de pedagogia na Unicentro}

Na tentativa de apresentar aqui a caminhada de professores e alunos na construção de um curso de graduação que tratasse especificamente dos estudos sobre a educação e a formação de professores, abordo, a partir das leis que o regulamentaram desde 1968 até os dias atuais, aspectos que possam nos conduzir a uma reflexão e a novas discussões em torno das questões da Pedagogia.

Inicialmente a Lei n ${ }^{\circ}$ 5.540/1968 aprovou a formação do pedagogo composta por uma base comum e por especialidades que compunham as habilitações. A base comum estava direcionada para atuação no ensino normal e as habilitações estavam direcionadas à formação de técnicos nas escolas cujas funções estariam especificadas no mercado de trabalho que ainda estava se constituindo. O curso foi reestruturado, nesta época, para atender as necessidades do mercado de trabalho e, essa concepção permaneceu até a LDB 9.394/96.

Tendo por base os estudos realizados por Brzezinski (2000) sobre a formação de docentes a partir da LDB/96, ampliaram-se as 
discussões em torno do curso de Pedagogia e, procurou-se organizá-lo de acordo com essa lei, proposta que vigorou entre 1996 a 2006.

$\mathrm{Na}$ atualidade, o curso segue uma nova estrutura respeitando-se as Diretrizes Curriculares nacionais aprovadas em maio de 2006.

\section{Lei 5.540/1968}

O curso de Pedagogia da Universidade Estadual do Centro Oeste - UNICENTRO, teve sua criação no ano de 1976, na Faculdade de Filosofia, Ciências e Letras de Guarapuava - FAFI.

Nesta época o curso foi organizado sob a forte influência da concepção tecnicista, presente na Lei 5.540/68, Parecer 252/69 e Resolução 02/69, do Conselho Federal de Educação, que fixou o currículo mínimo e a duração do curso de Pedagogia.

O curso era composto por disciplinas que formavam uma base comum, ou seja, as disciplinas pedagógicas para o Magistério do $2^{\circ}$ grau e outra parte era composta por disciplinas específicas das habilitações de Orientação Educacional e Administração Escolar.

Apresentavam como objetivo:

a) Que a Orientação Educacional possa subsidiar o profissional do ensino no tocante a compreensão do processo ensino-aprendizagem partindo do aluno para o todo no ato pedagógico, devendo-se voltar para as discussões quanto a politecnia e a terceirização, que são objetos de preocupação de uma sociedade produtiva e transformadora.

b) A Administração Escolar através de uma sólida fundamentação teórica aliada instrumentalização técnica, possa permitir uma atuação mais eficaz tornando-o capaz e consciente de seu papel na realidade escolar. c) O Magistério sendo o tronco comum do curso de Pedagogia deverá possibilitar ao pedagogo maior participação nos desafios que representam a educação brasileira com a bagagem científica e profissional oferecida pelo curso. (DEDUC/UNICENTRO, 1996, p. 3)

Sendo assim, foi definida a primeira matriz curricular para o curso de Pedagogia com as seguintes disciplinas:

- para a $1^{\text {a }}$ série Sociologia geral, Psicologia geral, Introdução a filosofia, Estrutura e funcionamento do ensino de $1^{\circ}$ e $2^{\circ}$ graus, Estatística aplicada a educação, Métodos e técnicas de pesquisa e Português, Prática desportiva;

- para a $2^{a}$ série Sociologia da educação, História da educação, Filosofia da educação, Psicologia da educação, Didática e Pesquisa pedagógica;

- para a $3^{\mathrm{a}}$ série Psicologia da educação, História da educação, Filosofia da educação, Psicologia das relações humanas, Didática, Educação pré-escolar e Metodologia do ensino de $1^{\circ}$ e $2^{\circ}$ graus; - para a $4^{\mathrm{a}}$ série Distúrbios de aprendizagem, Educação pré-escolar, Metodologia do ensino de $1^{\circ}$ e $2^{\circ}$ graus e Estágio supervisionado. (DEDUC/UNICENTRO, 1996, p. 5.)

Junto a essa formação tinha-se como referência outros campos do conhecimento, especialmente, da psicologia e do modelo de organização do trabalho taylorista/fordista.

Quanto a Psicologia vê-se que tem um destaque maior que outras, com 5 disciplinas distribuídas nas 4 séries do curso.

Essa influência da psicologia na educação vem, a nosso ver, de uma evolução histórica presente nas tendências pedagógicas desde o chamado ensino tradicional, que, de acordo com Mizukami (1996) o período que abrangia a fase dos jesuítas até os primeiros 
anos da república, com alguns resquícios que indicava uma pequena aproximação com o associacionismo inglês de Locke.

A tendência escolanovista - de 19301950, dividia-se em progressivista que tinha relações com a psicologia pragmática-funcional de Dewey e a antiautoritária que se traduzia por uma crítica ao autoritarismo cujo maior expoente era Neil(1963). O movimento da Escola Nova, que ocorreu na Rússia e depois se espalhou pela Europa, disseminou suas concepções com base na ciência psicológica com o intuito de buscar soluções e alternativas às dificuldades encontradas no ensino-aprendizagem. No Brasil, o educador brasileiro Anísio Teixeira consolidou estes princípios no país, influenciado especialmente pela psicologia norte-americana de corrente funcionalista-pragmática.

Entre 1960 a 1970 a tendência tecnicista era baseada no behaviorismo skineriano e, de 1980 para frente, a tendência crítico-social dos conteúdos com influência da psicologia cognitivista, ou seja, do construtivismo piagetiano à sócio-histórica corrente soviética de Vigotski, Luria e Leontiev.

Esta presença marcante da psicologia na formação de professores descartava a possibilidade de se aprofundar o caráter ideológico da dimensão política e das contradições e conflitos existentes na escola e na sociedade em que a psicologia não dava conta de todas as variáveis presentes na prática educativa.

No decorrer da história vemos a pretensão de uma pedagogia científica fundamentada na psicologia que acabou por considerar outras ciências importantes para a teoria e a prática educativas nos dias de hoje.

Quanto a organização do trabalho baseada numa concepção taylorista/fordista apontamos, com o estudo realizado por Valente (1999), três momentos distintos dentro do setor produtivo da sociedade que caracterizam esse modelo. O primeiro foi a produção artesanal com profissionais habilitados, que se utilizavam de ferramentas flexíveis, às vezes confeccionadas pelo próprio artesão. A produção era exclusiva, com alta qualidade e pouca quantidade. Daí os custos altos, fazendo com que o próprio artesão, muitas vezes, não pudesse dispor dos produtos que produzia.

O segundo momento foi a tentativa de democratizar o acesso a esses bens para um maior número de pessoas: era o modelo fordista ou de produção de massa. Esse modelo permitiu maior produção com menores custos, basicamente através da linha de montagem, em que a produção era "empurrada" de um funcionário a outro e, por fim, ao cliente.

Nesse processo, subpeças eram acopladas ao produto uma a uma, não exigindo muita habilidade do funcionário. As ferramentas geralmente eram fixas em setores. Sua base produtiva era composta de imigrantes de diversas nacionalidades, o que contribuía para o trabalho individual, dispensando o diálogo. Ao final da linha, o produto era testado e, ao satisfazer às exigências, era enviado para o mercado, e se constatado algum defeito, seria corrigido ou descartado.

O terceiro momento é caracterizado, por Valente, pela participação dos japoneses com o sistema de produção enxuta. Esse modelo se propôs a reagrupar o modelo artesanal com o modelo de produção em massa. Combina a grande variedade e a grande qualidade do modelo artesanal com o baixo custo e a grande quantidade do sistema de produção em massa. Nesse sistema, a produção é desencadeada pelo cliente, que "puxa" a produção. Assim, elimina-se o estoque e a produção é realizada na hora em que é solicitada. É dada a oportunidade de escolher alguns itens dentre a gama de possibilidades que o produto oferece e, com isso, ocorre a sensação de que o 
produto tenha sido feito especialmente para o cliente nos moldes da produção artesanal.

Essa possibilidade de opções exigiu planejamento constante, decisões rápidas e capacidade de compreensão das totalidades, levando-nos ao momento em que o conhecimento passa a ser o elemento necessário para melhoria da produção.

A educação, como os demais setores da sociedade, recebeu os reflexos dessas mudanças e tentou se adequar a elas na medida do possível, com projetos diversificados e alternativos.

No período artesanal havia a contratação do mentor para educar os membros da corte ou os filhos de famílias mais ricas. Poucos tinham aceso à educação, já que a produção era basicamente agrícola.

No modelo fordista, a educação era baseada em “empurrar” a informação para o aluno. A escola, vista como linha de montagem, organizou-se com tal estrutura.

O curso de Pedagogia quando passa a ser proposto com uma estrutura em forma de habilitações, subordina a educação à essa lógica do mercado fragmentando o conhecimento.

Ao que parece o problema do encaminhamento que se deu à questão do curso de Pedagogia reside numa concepção que subordina a educação à lógica de mercado. Assim, a formação ministrada nas escolas deveria servir à produtividade social, ajustando-se o mais completamente possível às demandas do mercado de trabalho que, por sua vez, são determinadas pelas leis que regem uma sociedade de mercado como esta em que vivemos. Nestas circunstâncias a questão educativa é reduzida dominantemente à sua dimensão técnica afastando-se o seu caráter de arte e secundarizando, também, as exigências de embasamento científico. (SAVIANI, 2007, p. 121)
Nesta proposta do curso de Pedagogia, o acadêmico poderia concluí-lo em 4 anos caso desejasse atuar no Magistério para o $2^{\circ}$ grau, ou ao contrário, poderia cursar mais um ano obtendo uma habilitação em Administração Escolar ou Orientação Educacional.

As disciplinas próprias da habilitação Administração Escolar eram introduzidas a partir da $3^{\mathrm{a}}$ série, num total de 7 disciplinas, iniciando-se por uma técnica instrumental (Currículos e Programas), duas teórico-metodológicas (Princípios e Métodos de Administração Escolar e Administração da Escola) na $4^{\mathrm{a}}$ série e, mais 3 instrumentais (Princípios e Métodos de Administração Escolar, Planejamento Educacional, Administração da Escola de $1^{\circ}$ e $2^{\circ}$ graus) na $5^{\mathrm{a}}$ série juntamente com uma prática operacional (Estágio Supervisionado).

As disciplinas próprias da habilitação em Orientação Educacional eram compostas por uma disciplina instrumental (Medidas Educacionais) na $3^{\text {a }}$ série, duas disciplinas teórico-metodológicas (Princípios e Métodos de Orientação Educacional e Orientação vocacional) na $4^{a}$ série, três disciplinas instrumentais (Princípios e Métodos de Orientação Educacional, Orientação Vocacional e Orientação Escolar) na $5^{\text {a }}$ série juntamente com uma prática operacional (Estágio Supervisionado). (DEDUC/ UNICENTRO, 1996)

De acordo com o Projeto Político Pedagógico do Curso (1996-1998, p.10) o que se observa é a constituição de um quadro curricular composto por 25 disciplinas no tronco comum sendo que destas 11 eram teóricas, 12 teórico-práticas e duas de caráter prático.

O pólo prático dos componentes curriculares restringia-se à Prática Desportiva e ao Estágio Supervisionado. Salienta-se que grande parte dos acadêmicos não freqüentava a disciplina de Prática Desportiva em vista de que eram trabalhadores diurnos e podiam ser 
dispensados por lei, “o percentual de alunos trabalhadores é de cerca de $90 \%$ no noturno e, de 70\% no diurno” (p.7)

Observa-se, na composição da matriz curricular, um número maior das disciplinas teórico-práticas seguidas das teóricas, subentendendo-se que ambas foram pensadas para subsidiar o Estágio. Parece que, com esta característica o Estágio Supervisionado, não estava satisfazendo às expectativas nem do corpo docente nem discente, devido, talvez à forma como o Estágio vinha sendo configurado, ou seja, ao em vez de fazer parte no contexto do quadro curricular estava sendo realizado apenas no final do curso.

Articular os conhecimentos teórico-práticos consiste em perceber a educação como práxis, de forma que o ofício da profissão professor se faça pelo conhecimento convertido em ação. Mas diante da formação fragmentada e da frágil articulação entre teoria e prática, muitas vezes, presente no curso de pedagogia que, especialmente nos primeiros anos de funcionamento, entendeu por prática o estágio supervisionado oferecido no final do curso, prevalecendo a concepção de que uma parece estar distante da outra, era contraditório. E, isso foi percebido pelo grupo tanto que, na proposta seguinte procura contemplar a prática de ensino já a partir da $1^{\mathrm{a}}$ série.

Assim, a formação geral do pedagogo vinha se constituindo numa carga teórica maior com pouca convergência para a experimentação prática cotidiana e a teoria trabalhada, muitas vezes, se perdia ao caminhar para esta prática. Isso se tornava evidente na dificuldade que os alunos apresentavam quando necessitavam resgatar, na construção de um plano de atividades, conteúdos já trabalhados anteriormente. É o que passa a ser discutido na proposta que se segue a esta: "O quadro curricular tem sido desenvolvido de forma contrária à interdisciplinaridade o que reflete no Estágio Supervisionado - única oportunidade de vivência prática. Ainda não se conseguiu envolver todas as disciplinas do curso num todo contínuo e articulado com matizes práticos e teóricos de forma a subsidiar o ensino crítico.” (DEDUC/UNICENTRO, 1996, p.4)

Porém, nem as funções especificadas para os especialistas em Administração Escolar e Orientação Educacional estavam bem caracterizadas, pois não havia se constituído ainda o espaço de atuação em que estes profissionais pudessem exercer as habilitações propostas.

Essa formação em habilitações é questionada nos anos de 1980, quando os movimentos sociais se fortalecem propondo mudanças, inclusive no campo educacional, numa linha de pensamento voltada para o entendimento das contradições existentes na realidade escolar. É quando acontece a $1^{\text {a }}$ Conferência Brasileira de Educação que vai culminar na constituição da Associação Nacional pela Formação dos Profissionais da Educação - ANFOPE, atualmente em atividade.

No final da década de 1980 e início de 1990, observa-se o desenvolvimento de uma nova ordem econômica orientada pelos princípios do neoliberalismo que exige uma série de reformas em diferentes segmentos e setores da sociedade. Essas reformas tinham como pressuposto a ênfase no Estado Mínimo, cujas políticas sociais centravam-se na racionalidade, produtividade e eficiência.

O curso, a partir de então, começou a ser repensado por conta da expansão didático-pedagógica da Universidade que, no ano de 1990 teve seu reconhecimento e, pelo fato de que estaria sendo promulgada a nova Lei de Diretrizes e Bases da Educação Nacional 9.394 em 1996. 
Neste contexto, o profissional da educação precisou encontrar formas de trabalhar com as contradições reais ou aparentes da realidade possível, de um lado havia uma formação que atendia a uma realidade, de outro os órgãos públicos lançavam editais com uma exigência de formação diferenciada. A fragmentação da formação do pedagogo em especialidades estava sendo questionada pela LDB/96 e, conforme Brzezinski (2000) a lei não deu o devido valor a este profissional especialmente quanto ao artigo 64 que afirma “a formação dos profissionais da educação para a administração, planejamento, inspeção, supervisão e orientação educacional para a educação básica, será feita em cursos de graduação em pedagogia ou em nível de pós-graduação, a critério da instituição de ensino garantida nesta formação a base comum nacional” - grifo nosso - (LDB 9.394, 1996, p. 18).

Por outro lado, havia era um período que caracterizava-se por uma transição paradigmática da ciência moderna para uma ciência pós-moderna que significaria novas concepções no papel do pedagogo.

\section{Lei de diretrizes e bases da educação nacional $n^{0}$ 9.394/1996}

No bojo dessas mudanças, ocorreu uma série de discussões em relação aos cursos de licenciatura, entre eles o curso de Pedagogia. As Organizações Educacionais manifestaram-se contrárias a vários artigos da lei que se referem ao curso como um dos pontos que segue abaixo:

O estabelecimento da Lei ${ }^{\circ} 9.394$ de 20 de dezembro de 1996 ao criar os Institutos Superiores de Educação (ISEs) e o Curso Normal Superior (CNS), tornou a questão da identidade legal do Curso de Pedagogia em um dos temas mais polêmicos e de complexa regulamentação na área da graduação. Mas, gerou, igualmente, situações inadequadas em relação aos demais cursos de formação de professores. (FORUMDIR, 2004/p.1)

No meio destas discussões dois aspectos fundamentaram o direcionamento do Curso de Pedagogia para que fossem efetivamente inseridas no cotidiano do processo educacional: os conteúdos que reforçam a dimensão teórica e a dimensão prática.

Concebendo a pedagogia na base do que move o processo educacional no cotidiano, ou seja, o seu saber-fazer situado em contexto de interação de humanos com humanos, essas duas vertentes são essencialmente integradas e inseparáveis. Essa compreensão aponta, portanto, para uma práxis transformadora repleta de intencionalidade que se expressa na conceituação de trabalho voltado para a emancipação profissional e humana de sujeitos. (FORUMDIR, 2004/p.2)

Com o intuito de acompanhar estas discussões em nível local e nacional, a UNICENTRO, coincidentemente à época, determinou a obrigatoriedade da instalação do Colegiado para todos os cursos da Instituição. O coordenador do Colegiado, representante pedagógico legal do curso, tinha como função, realizar as novas adequações da matriz curricular e encaminhar as discussões para elaboração do novo Projeto Político Pedagógico, de acordo com as determinações da legislação adotando um currículo voltado à formação de licenciados ao Magistério dos Anos Iniciais e introduzindo as habilitações de Educação Infantil e Supervisão Escolar.

O Colegiado de curso era uma instância do Departamento composta por professores que atendiam as disciplinas de seu curso e de outros cursos. Cursos em que as disciplinas eram ministradas por professores do 
Departamento de Pedagogia tinham em seu colegiado professores desse departamento e vice-versa, para discutir as questões referentes ao seu curso. Portanto, o Departamento de Pedagogia tinha representantes em, praticamente, todos os cursos da Instituição, o que, de certo modo, proporcionou uma visualização didático-pedagógica abrangente, das ações realizadas pelo corpo docente do Departamento.

Isso fez com que as perspectivas em torno das mudanças geradas pela nova legislação pudessem ser levadas, não apenas para o curso de Pedagogia, como também para os demais cursos.

Delineando novas expectativas para o curso, foi aprovada a proposta de extinguir a partir de então, a formação de professores para o Ensino Normal e passou a ter 4 habilitações cujos objetivos podem ser assim descritos:

- concretizar os propósitos pedagógicos e políticos desta Universidade, no sentido da difusão das possibilidades de formação de professores em nível superior, para atuação no magistério das séries iniciais do ensino fundamental;

- atender ao que dispõe a LDB da Educação nacional, no que concerne à formação do profissional para o trabalho, à promoção e divulgação de conhecimentos culturais, científicos e técnicos, que constituem o patrimônio da humanidade, à comunicação do saber por meio de ensino, de publicações ou de outras formas de comunicação, visando colaborar com a formação contínua do profissional da educação.

- otimizar o "aproveitamento" do capital humano qualificado e disponível na Universidade, com vistas a atender tanto a exigência legal, quanto a real demanda social de professores em busca de formação de nível superior, para atuação nas séries iniciais do ensino fundamental. (DEPED/ UNICENTRO, 2000, p. 83)
Com estes objetivos o Departamento parece estar preocupado em atender a legislação e a Instituição. Outros objetivos são apresentados com o mesmo tom de formar docentes para as séries iniciais por meio do ensino superior uma vez que aos Colégios de nível médio é determinada a extinção dos cursos de magistério.

Alguns aspectos que passaram a configurar a nova proposta merecem ser destacados para maior análise para atender as especificidades locais e a LDB/96, dentre estes destacamos, a inserção de competências e habilidades como forma de caracterizar o curso numa perspectiva diferenciada da anterior, a interdisciplinaridade, a contextualização e a articulação do ensino com a pesquisa.

À formação do pedagogo procurou-se assegurar o desenvolvimento de competências e habilidades intelectuais, comprometidas com a construção de uma realidade social que abrangiam desde a Educação Infantil e o Ensino Fundamental até a organização e coordenação de escola. O objetivo maior estava pautado em oferecer um ensino de qualidade, tendo sua base constituída por uma perspectiva em que destacavam as seguintes competências e habilidades:

- compreensão ampla e consistente do fenômeno e da prática educativa que se dão em diferentes âmbitos e especificidade; compreensão do processo de construção do conhecimento no indivíduo inserido em seu contexto social e cultural;

- capacidade de identificar problemas sócio-culturais e educacionais propondo respostas criativas às questões da qualidade do ensino e medidas que visem a superar a exclusão social;

- capacidade de articular ensino e pesquisa na produção do conhecimento e da prática pedagógica; 
- capacidade de desenvolver metodologia e materiais pedagógicos adequados á utilização as tecnologias da informação e comunicação nas práticas educativas; - compromisso com uma ética de atuação profissional e com a organização democrática da sociedade;

- articulação da atividade educacional nas diferentes formas de gestão educacional, na organização do trabalho pedagógico, no planejamento, execução e avaliação de propostas pedagógicas na escola;

- compreensão dos pressupostos avaliativos do processo educativo. (PROPOSTA DE ADEQUAÇÃO CURRICULAR, 1998, p.11)

Quando tratamos de competência, estamos tratando de um termo que possui flexibilidade, ou seja, permite se realizar um ensino criando condições para que o outro adquira conhecimentos, habilidades, linguagens, valores culturais e emocionais relacionados à capacidade de realizar ou resolver uma situação complexa. “As competências pressupõem operações mentais, capacidades para usar as habilidades, emprego de atitudes adequadas á realização de tarefas e conhecimentos.” (BORDONI, 2008, p.1)

As competências e habilidades propostas então, parecem se adequar ao conceito acima, porém vemos, na caracterização do curso e na matriz curricular uma ampliação de conteúdos associando maior competência à maior quantidade de conteúdos. No Projeto Pedagógico anterior tínhamos um eixo comum com 25 disciplinas e um curso de 4 anos e, nesta Proposta um eixo comum com 27 disciplinas e mais 1 ano para obter uma habilitação, ou seja, a formação do pedagogo especialista aconteceria em 5 anos.

Procurou-se também utilizar o princípio da flexibilização curricular de forma que se tivesse um leque maior de opções, visando ampliar a formação geral e o desenvolvimento das competências e habilidades específicas, além de oferecer também um rol de disciplinas optativas para aprofundamento em outras áreas de interesse.

O curso passou a ter, então a seguinte organização:

1- Base comum - que contemplava os fundamentos sociológicos, filosóficos, psicológicos e históricos, políticos e antropológicos, assim como as questões relativas ao trabalho pedagógico e a gestão escolar, constituindo o que se denominou de núcleo-histórico-contextual, ou seja, são as disciplinas que tratam dos conhecimentos estruturantes do curso;

2- Eixo integrador do curso - com a inserção da disciplina de Pesquisa em Educação I, II e III na $1^{\text {a }}$, $2^{\mathrm{a}}$ e $4^{\mathrm{a}}$ séries respectivamente, procurou-se apresentar os fundamentos investigativos e reflexivos na área educacional, eram disciplinas de conhecimento intercomplementares, ou seja, aquelas que forneciam o elo de ligação com os demais núcleos e disciplinas, além de propiciar estudos sobre diferentes modos de pesquisar, de olhar e de captar a escola e a prática que nela se realizava. A proposta de promover a interação do cotidiano da escola com a teoria, tinha como meta propiciar um olhar crítico da realidade e, assim, orientar a elaboração do projeto e do trabalho final de pesquisa. Este procedimento foi o ponto de partida para que ao longo do curso se pudesse formar o professor-pesquisador de sua própria prática pedagógica. A sistematização do trabalho de pesquisa aconteceria com o Trabalho de Conclusão de Curso, o qual era socializado em seminários de pesquisa e outros eventos no âmbito da Instituição ou de outras Instituições. Esta perspectiva na formação do pedagogo implicou na iniciação à formação do pesquisador em educação o que, até então, era concebido, geralmente na pós-graduação, pois além de articular a formação do professor em pesquisa para aplicá-la em sala de aula, lugar privilegiado da produção do 
conhecimento, favorecia a construção do saber e desenvolvimento do processo crítico do conhecimento.

3- Núcleo dos conteúdos didático-metodológico-profissionais - constituía-se pelos fundamentos e conteúdos curriculares da educação básica, conhecimentos didáticos e as disciplinas de conhecimentos específicos, além da necessária articulação com a prática de ensino denominada, neste contexto, como prática pedagógica que se iniciava pela observação do cotidiano escolar, passando pelas etapas de atuação em mini cursos, seminários, palestras, observações participativas e estágios supervisionados. Neste enfoque as disciplinas pertencentes a este núcleo eram, aqui, entendidas como princípios pedagógicos gerais que norteavam a organização do trabalho em sala de aula e sua articulação com a organização global da escola.

4- Núcleo complementar - compreendia as disciplinas que veiculavam conteúdos complementares à estrutura do curso como Pedagogia e Movimento, Tecnologias de Comunicação e Informação, incluindo neste contexto as disciplinas optativas e eletivas as quais aprofundavam a análise e a crítica da conjuntura educacional brasileira além de propiciar aos alunos um entendimento significativo dos diversos segmentos de atuação do pedagogo.

FONTE: DEDUC/UNICENTRO, 2000.

Outro aspecto a mencionar é a interdisciplinaridade pensada no curso como uma linha metodológica a ser utilizada nos diversos núcleos das disciplinas ou entre as disciplinas.

A interdisciplinaridade como elemento integrado, poderia ter acontecido ou ter sido pensada de forma a se criar possibilidades de efetivá-la. Porém não fica claro no documento como esta linha poderia se realizar, a apresentação do termo é bastante confusa, como vemos

\begin{abstract}
A interdisciplinaridade (...) porque ela pode ser também compreendida se considerarmos a relação entre o pensar e o agir. Sendo assim, todas as linguagens trabalhadas pelo curso, nas diferentes disciplinas, são, por natureza, "interdisciplinares," por estarem alicerçadas na formação de professores e professoras, em que os conteúdos curriculares se constituem em conhecimentos, isto é, significados que ao serem formalizados por alguma linguagem tornam-se mais significativos.” (DEPED/UNICENTRO, 2000, p.12)
\end{abstract}

No entanto, entende-se por interdisciplinaridade,

a interação existente entre duas ou mais disciplinas. Essa interação pode ir da simples comunicação de idéias à integração mútua dos conceitos diretores da epistemologia, da terminologia, da metodologia, dos procedimentos, dos dados e da organização referentes ao ensino e à pesquisa. Um grupo interdisciplinar compõe-se de pessoas que receberam sua formação em diferentes domínios do conhecimento (disciplinas) com seus métodos, conceitos, dados e termos próprios. (FAZENDA, 1996, p. 27)

Com isso, não há um encaminhamento na estrutura do curso nesta direção, nem mesmo aponta como ela poderá acontecer pelas diversas disciplinas além do mais, partindo dessa linha metodológica segue-se para um mecanismo metodológico em que tem seu alicerce na contextualização. Estes termos grifados, empregados na Proposta de Adequação Curricular ora em questão, não trazem elementos conceituais mais objetivos para sua compreensão na organização do curso que corresponda aos demais aspectos numa abordagem que, se pretende, como integradora.

Um último aspecto está relacionado à articulação entre ensino e pesquisa que "trata-se da viabilização da iniciação científica 
como instrumentalização necessária a todos os alunos e alunas, professores e professoras em formação, pelo reconhecimento de todos como produtores de conhecimento.” (DEPED/UNICENTRO, 2000,p. 14 )

Nessa linha de construção do profissional é que se pretendeu delinear a estrutura organizacional do curso, tendo como eixo norteador a formação do professor pesquisador com ênfase na análise crítica e investigativa dos problemas da prática pedagógica que possibilitassem a intervenção no processo da própria formação. Esta orientação justificou a especificidade do Trabalho de Conclusão de Curso como parte integrante da matriz que atendesse a perspectiva de formação do professor pesquisador no interior da graduação, articulando-a com o exercício profissional nos diversos âmbitos escolares.

A formação do professor-pesquisador passou a ser uma alternativa para minimizar ou eliminar as dicotomias que dificultavam os processos mais positivos da produção do conhecimento, ao mesmo tempo em que se evidenciava a articulação teoria e prática como atividades integradoras na formação de professores, as quais operacionalizadas na organização curricular como dimensões de um mesmo processo, possibilitaria a flexibilização vertical e horizontal do currículo na formação de saberes. Ou melhor, se pretendia que a partir desta concepção da pesquisa no curso, pudesse ter sua continuidade na construção de um projeto de curso de Mestrado em Educação.

A proposta se delineava da seguinte forma: as disciplinas de Pesquisa em Educação I e Pesquisa em Educação II ministradas na $1^{\mathrm{a}}$ e $2^{\mathrm{a}}$ séries se traduziam pela inserção do acadêmico na realidade escolar onde eram orientados a realizar um trabalho numa linha investigativa-exploratória, sugeria-se a participação em atividades de pesquisa e extensão durante o curso. Paralelamente a estas disciplinas, como parte do núcleo dos conteúdos didático-metodológicos encontravam-se as disciplinas de Prática Pedagógica I e II que procuravam responder as questões curriculares na vivência do cotidiano escolar, propiciando a constante participação em situações práticas, permitindo, aos acadêmicos, reconstruir conhecimentos teóricos trabalhados no curso. Na série seguinte, como não havia uma disciplina específica de Pesquisa, a Prática Pedagógica III - Estágio Profissional, articulava os conhecimentos construídos anteriormente com o fazer pedagógico, junto às metodologias específicas. E, por fim, na $4^{\mathrm{a}}$ série, estava alocada a disciplina de Trabalho de conclusão de Curso, momento em que finalizava o trabalho científico a partir das experiências vivenciadas durante o curso.

Além disso, procurou-se inserir na matriz curricular do curso, uma disciplina que atendesse as tecnologias de informação e comunicação de modo que o profissional pudesse desenvolver conhecimentos na manipulação de programas, aplicativos e domínio da internet para a realização de atividades pedagógicas, conhecer as reações que se estabeleciam entre os setores no interior do processo produtivo e a formação do educador face às expectativas das áreas sociais e dos serviços integrados à educação.

Cabe ressaltar ainda como uma aprendizagem essencial ao pedagogo, o domínio de saberes de natureza ética, necessários à compreensão e análise das articulações entre a proposta pedagógica e a visão de sociedade e de humanidade, além da capacidade de assumir compromisso político na realização das propostas pedagógicas nos diversos níveis de ensino nas instituições educacionais.

Em processo de reconhecimento, vale ressaltar que esta proposta curricular veio a sofrer novas reformulações para os anos 
seguintes, com alterações de nomenclaturas de algumas disciplinas já constantes na matriz, como também foram inseridas novas disciplinas.

A partir do ano 2001, o curso de Pedagogia passou a ser ofertado nos Municípios de Laranjeiras do Sul e Pitanga em regime de extensão e, nesta ocasião os membros do Conselho Estadual de Educação do Paraná, acabaram por sugerir que se levasse em consideração também, as discussões ocorridas em âmbito mundial, o que levou os professores do Departamento de Pedagogia a buscar uma articulação entre as necessidades locais e o contexto mundial.

Esse estudo levou o Departamento de Pedagogia a propor a habilitação de Educação Inclusiva a fim de formar profissionais para a chamada Educação Especial com o objetivo de atender uma importante demanda social e, aberto um novo mercado para o pedagogo. De forma ampliada e melhorada, a habilitação em Educação Inclusiva substituiu a formação, que até então era possível, através dos Estudos Adicionais.

Outro elemento importante na construção desta proposta estava o cuidado com o interesse e as especificidades da região de abrangência da Instituição, de forma a permitir que os acadêmicos pudessem cursar uma parte do currículo em comum e a outra de modo mais flexível. A intenção era propor uma formação baseada numa práxis pedagógica reflexiva. A formação múltipla, que acontecia pela escolha de uma habilitação, contemplava os diferentes interesses e possibilidades para os alunos e, correspondia ao domínio do conteúdo científico pedagógico capaz de oferecer condições para uma prática educacional de intervenção consistente e explicativa da realidade pelas dimensões profissional, epistemológica, política e criativa.
Quanto ao Estágio Supervisionado, foram destinadas 300 horas de Prática Pedagógica, distribuídas ao longo do curso desde a $1^{\text {a }}$ série considerando aspectos previstos no art. 65 da LDB/1996 como:

- a prática de ensino deve nortear a formação docente no intuito de superar a visão fragmentada existente nos currículos, em que se desconsidera a teoria como fundamentação preliminar e a prática como aplicação dos conhecimentos obtidos além das situações criadas artificialmente nos contextos escolares;

- a prática de ensino possibilita um trabalho coletivo interdisciplinar entre os acadêmicos e entre os professores, no movimento curricular, com valorização das experiências e vivências concretas dos envolvidos no que tange às práticas de educação.

A partir desses pressupostos, pretendia-se que a Prática de Ensino no curso fosse integrada com as disciplinas do núcleo didático-metodológico-profissional e articulada com a pesquisa, considerando que as demais disciplinas pertencentes à matriz curricular no que se referia aos procedimentos didático-metodológicos contribuíssem na execução de atividades, na busca de observação e reflexão e na iniciativa de enfrentamento de situações complexas no processo de construção de identidades profissionais para os acadêmicos do curso.

Com um projeto de formação de professores procura-se desenvolver uma metodologia de trabalho coerente com o tipo de prática pedagógica que se pretende com os alunos. Os processos pedagógicos demandam coerência entre o currículo de formação e o currículo que se deseja aplicar aos alunos. Parece que houve essa tentativa na organização do curso, porém ficou faltando esclarecer melhor sua operacionalização. 


\section{Diretrizes curriculares nacionais para o curso de pedagogia - res. Cne/cp $n^{0} 1,15 / 05 / 2006$}

Embora sendo muito questionado o Projeto de Resolução que instituiu as diretrizes curriculares para o curso de Pedagogia, os temas mais polêmicos permaneceram na Resolução posteriormente aprovada como, por exemplo:

- a elevação do curso Normal Superior à condição de curso de Pedagogia com 2.800 que desconsideraram a duração do curso de 3.200;

- a dicotomia entre licenciatura e bacharelado;

- o caráter assistencialista do curso entre outros.

A insegurança na organização de um novo Projeto de Curso aumentava por conta destes embates e pela falta de uma diretriz definida que somente foi aprovada em maio de 2006, a Res. CNE/CP Nº1 de 15/05/2006.

A mobilização dos educadores e demais órgãos relacionados à formação de professores foi importante para o debate sobre as experiências e a política educacional e para socializar reflexões e angústias que pudessem apontar um caminho para o curso que, por fim, colocou a docência como eixo principal da formação e estabeleceu uma base comum que ainda não tem muito clara uma definição de que forma poderá ser concretizada.questões, especialmente no que se referiu ao Normal Superior, foi motivo de polêmica, pois observava-se um crescimento bastante significativo deste curso na região.

Mesmo sem uma definição, no ano de 2005, reiniciando o processo de estudo em torno do curso, o Departamento de Pedagogia, procurou acompanhar a flexibilização no mercado de trabalho e as Diretrizes Curriculares sobre a formação do pedagogo. Tal contexto proporcionou condições para o debate sobre uma reformulação que não privilegiasse mais as especialidades/habilitações. O curso de Pedagogia passou a centrar-se na Docência e na Gestão Educacional em instituições escolares e não escolares enfatizando a pedagogia como ciência da educação e da formação de professores.

Visto que a opção pela docência tenha sido o eixo principal na formação do pedagogo, essa formação não se restringiu apenas ao aspecto técnico-pedagógico do espaço da sala de aula, mas sim, compreendeu outros espaços possíveis para a organização do trabalho pedagógico.

Junto a essa formação inicial, procurou-se também contemplar a formação continuada na Proposta Curricular de 2006 para possibilitar, além da qualificação profissional para a Docência nos anos iniciais, na educação infantil, nas disciplinas pedagógicas do ensino médio - modalidade normal - e para a Gestão educacional, "a formação continuada em nível de pós-graduação nas áreas emergentes da educação que não estariam sendo ofertadas na graduação como, por exemplo, a Supervisão Escolar e outros.” (DEPED/ UNICENTRO, 2000, p. 23)

Podemos inferir que, embora o Departamento tenha atendido as Diretrizes Curriculares, a concepção fragmentada em habilitações ainda estava muito presente, pois o que não aparecia na graduação, passou a ser proposto na pós-graduação.

Aos argumentos anteriormente apresentados, somam-se o processo de diversificação das atividades pedagógicas, a ampliação do conceito de educação e o surgimento de novos sujeitos e espaços educativos, os quais solicitam uma visão plural de educação a partir de uma abordagem interativa.

A nova proposta do curso de Pedagogia baseada nas diretrizes curriculares de 2006, 
não apresentou modificações significativas em relação aos encaminhamentos teórico-metodológicos do projeto anterior, apenas sofreu uma adequação na matriz curricular.

A Educação Inclusiva, que estava como uma habilitação passou a ser configurada de uma forma transversal em que as ementas das disciplinas pudessem contemplar aspectos direcionados a pessoas portadoras de necessidades educacionais especiais. Ainda assim, a ela foram dedicadas duas disciplinas no curso como Fundamentos da Educação Especial e Noções de Língua Brasileira de Sinais - LIBRAS.

A pesquisa permaneceu como eixo comum do curso iniciando na $1^{\mathrm{a}}$ série com a disciplina de Pesquisa em Educação I, perpassando a $2^{\mathrm{a}}$ série com a disciplina de Pesquisa em Educação II e, finalizando com a Pesquisa em Educação III - Trabalho de Conclusão de Curso na $4^{a}$ série, com a mesma estrutura e objetivos em formar o professor-pesquisador articulada agora aos fundamentos da educação e às metodologias de ensino. Houve pretensão de vincular os projetos de pesquisa dos acadêmicos aos grupos de pesquisa dos professores do Departamento de Pedagogia com o intuito de, inicialmente, identificar as linhas de pesquisa que pudessem direcionar o projeto de curso de Mestrado para que, posteriormente se definisse, em estudo efetivo, uma proposta mais concreta de curso em nível strictu sensu.

O Estágio Supervisionado migrou da $1^{\mathrm{a}}$ série, o qual estava contemplado na disciplina de Prática Pedagógica, para a $3^{\text {a }}$ série em que, de acordo com as Diretrizes deveria ter seu início na segunda metade do curso, ou seja, a partir da $3^{\mathrm{a}}$ série. O Estágio passou então a ser realizado nas áreas que abrangiam a docência na educação infantil, nos anos iniciais (ambos na $3^{\text {a }}$ série ofertados em regime semestral) e nas disciplinas pedagógicas do ensino médio e em Gestão Educacional (na $4^{\mathrm{a}}$ série), todas com 68 horas.

As disciplinas dos fundamentos da educação (ministradas na $1^{\mathrm{a}}$ e na $2^{\mathrm{a}}$ séries) direcionaram em suas ementas subsídios aos acadêmicos para realização dos estágios nas disciplinas pedagógicas do ensino médio; as metodologias de ensino na $2^{\mathrm{a}}$ e $3^{\mathrm{a}}$ séries encaminharam subsídios para o estágio em educação infantil e nos anos iniciais.

Incluiu-se na matriz curricular a disciplina de Leitura e produção de texto para reforçar aspectos da utilização de uma linguagem científica para subsidiar o processo da pesquisa. Outra disciplina foi a que contemplasse a Língua Brasileira de Sinais LIBRAS que ficou alocada na $4^{\mathrm{a}}$ série.

Na proposta foi incluída a possibilidade de destinar um total de $20 \%$ da carga horária de cada disciplina para ser realizada a distância e, acrescentou-se no núcleo complementar, um mínimo de 100 horas para Atividades Complementares que correspondem à participação do acadêmico em eventos, projetos, publicações, seminários, cursos, etc. e, que, ao final do curso, a documentação correspondente deveria ser apresentada. Continuouse a enfatizar competências e habilidades como elementos necessários à formação do Pedagogo, porém não ficou explícito quem é esse pedagogo e quais suas atribuições, apenas salientou-se o seu espaço de atuação, "nas diferentes áreas da educação formal e não formal, em atividades científico-tecnológicas do campo educacional, na produção e na difusão de conhecimentos próprios desse campo, na organização e gestão de experiências educacionais escolares e não escolares (...).” (DEPED/UNICENTRO, 2006, p.15)

A Gestão escolar teve seus fundamentos estabelecidos paralelamente ao Estágio em Gestão na $4^{a}$ série, na qual, de certa forma, acumulou várias atividades como o trabalho 
de conclusão de curso, o estágio no ensino médio, o estágio em gestão e as atividades complementares.

Pela amplitude e abrangência do curso, a formação do Pedagogo envolveu uma série de mudanças. Vimos, dessa maneira, que o curso de Pedagogia, assim como as Diretrizes Curriculares revelam-se, conforme Saviani (2007, p. 127)

(...) extremamente restritas e demasiadamente extensivas; muito restritas no essencial e assaz excessivas nos acessórios. São restritas no que se refere ao essencial, isto é, àquilo que configura a pedagogia como um campo teórico-prático dotado de um acúmulo de conhecimentos e experiências resultantes de séculos de história. Mas são extensivas no acessório, isto é, se dilatam em múltiplas e reiterativas referências às linguagem hoje em evidência, impregnada de expressões como conhecimento ambiental-ecológico; pluralidade de visões de mundo; interdisciplinaridade, contextualização, democratização; ética e sensibilidade afetiva e estética; exclusões sociais, étnico-raciais, econômicas, culturais, religiosas, políticas; diversidade; diferenças;gêneros; faixas geracionais; escolhas sexuais (..)

Com isso, não podemos descartar que há grande quantidade de elementos a serem abordados na formação de professores como os mencionados por Saviani acima, e que são importantes e estão muito presentes no cotidiano escolar e na vida de cada indivíduo, mas precisam ser repensados em que medida devem ser incorporados no projeto pedagógico do curso, para que realmente atendam as necessidades acadêmicas e sociais.

\section{Partindo para uma conclusão e novos parâmetros}

A história descrita durante mais de uma década sobre o curso de Pedagogia na UNICENTRO, nos ensina algumas lições importantes e que valem a pena ser levadas em consideração:

1-Tratar sobre a formação do profissional pressupõe um processo dinâmico de aprendizagem, mudanças e melhorias. A aprendizagem, neste contexto, está estritamente relacionada ao conhecimento prático constituído por sua experiência, interesses, necessidades, resistências, dificuldades técnicas e habilidades para trabalhar no ambiente escolar. E, também pelo conhecimento teórico sobre o desenvolvimento e a aprendizagem dos alunos, os fundamentos que subsidiam os conteúdos e as técnicas de aplicação em situações práticas. Esses conhecimentos subjetivos e objetivos precisam ser considerados na formação a qual se caracteriza não somente pela apropriação dos fundamentos epistemológicos das teorias, mas também pela concepção do ensino como atividade prática.

2-Levar os professores ao estágio da autonomia é uma das prioridades em sua formação, o que possibilitará a elaboração de projetos de inovação institucional por meio de ações colaborativas. Por ser projetos coletivos de melhoria, o que demanda a participação e envolvimento dos professores, existe uma estreita relação entre a implementação de programas que resultem em desenvolvimento profissional do professor e o desenvolvimento da própria instituição escolar.

3-Por meio da investigação dos dados existentes relacionados à ação pedagógica dos alunos egressos do curso, poderá se ter um parâmetro significativo quanto a vários aspectos da educação como a elaboração de uma proposta de um curso de formação de professores. Refletindo sobre o próprio trabalho e o confrontando com os resultados 
da aprendizagem, o professor vai compreendendo melhor sua prática e se tornando crítico de si mesmo, e, ainda assume pessoalmente a formação continuada como uma exigência do processo de mudança.

Por fim, a formação dos profissionais da educação nas instituições, deve considerar a criação de uma cultura profissional que tenha como uma de suas características a mudança gradual do conhecimento dos professores, adquirido na sua vida experiencial profissional e social, para o conhecimento pedagógico especializado. Essa mudança gradual é um dos obstáculos que o projeto de formação de professores deve procurar evidenciar e tornar acessível.

Na trajetória percorrida até aqui, procurei apresentar uma análise descritiva da construção do Projeto Político Pedagógico do Curso de Pedagogia em três momentos.

O primeiro, a partir de 1976 quando da criação do curso, que enfatizava uma formação psicologizante e organizado dentro de um modelo taylorista/fordista representado pelo conhecimento técnico. Tinha um eixo comum na formação para o ensino normal e em duas habilitações, uma em Administração Escolar outra em Orientação Educacional

O segundo Projeto, a partir da LDB 9.394/96, estava direcionado a uma abordagem baseada em competências e habilidades, bem como a relação entre ensino e pesquisa e, também a uma intencionalidade que colocava a interdisciplinaridade e a contextualização como viés do curso, mas que, por seu pouco aprofundamento e maiores esclarecimentos na proposta, nos pareceu inoperante. $\mathrm{O}$ eixo comum passou a ser a formação para os anos iniciais e a inserção das habilitações de Supervisão Escolar, Educação Infantil, Educação Inclusiva somadas às já existentes.

Há que se considerar, nesse percurso, a expansão didático-pedagógica da
UNICENTRO que automaticamente levou o Departamento a ampliar o curso, ofertando o Curso em regime de Extensão para três Municípios.

Em um terceiro Projeto, tendo por base as Diretrizes Curriculares, poucas alterações ocorreram no âmbito das concepções do curso, permanecendo os objetivos e princípios, a relação entre ensino e pesquisa, inserindo-se novas competências e habilidades. O curso passou a ser organizado na docência e na gestão educacional em instituições escolares e não-escolares, extinguindo-se as habilitações.

$\mathrm{Na}$ atualidade, o fato de o curso contemplar a formação do Pedagogo para atuar em espaços diversificados, o curso vem apresentando um aumento na demanda não só na sede como nos demais Campi Avançados.

Isso ocorreu devido a um compromisso do Departamento com a qualidade no ensino, respeitando-se a legislação nacional e procurando atender a necessidade do mercado de trabalho, especialmente da rede pública de ensino, que se abriu para a função de Pedagogo.

O Departamento de Pedagogia da UNICENTRO, com o intuito de organizar um curso nesta perspectiva, demonstrou as suas dificuldades e avanços, de certo modo, bastante significativos na formação do Pedagogo no Município e, em sua região de abrangência e, a partir dos registros descritos podemos inferir novos encaminhamentos para uma nova proposta de curso.

\section{Referências bibliográficas}

ALMEIDA, I. M. M. Z. P. de A formação continuada e a re-significação do papel da psicologia da educação para os professores de ciências e matemática. Disponível em < http://www.fe.unb.br/linhascriticas/n17/a_ formacao_continuada.html $>$ Linhas Críticas. Revista da Faculdade de Educação: 
Brasília: UNB. Acessado em 30 de mar. 2008.

BORDONI, T. Saber e fazer...competências e habilidades?!? Disponível em < http://www. pedagobrasil.com.br/pedagogia/saberefazer. htm $>$ On line. Acessado em 30 de março de 2008.

BRZEZINSKI, I. A formação e a carreira de profissionais da educação na LDB 9.394/96: possibilidades e perplexidades. In: (org.) LDB interpretada: diversos olhares se entrecruzam. 3.ed. São Paulo: Cortez, 2000. P. 147-168.

DEPARTAMENTO DE EDUCAÇÃO. Projeto político pedagógico 1996-1998. Guarapuava: UNICENTRO.

- Proposta de adequação

curricular. Guarapuava: UNICENTRO, 2000

- Projeto político

pedagógico. Guarapuava: UNICENTRO, 2006.

DREIFUSS,R.A.Aépocadasperplexidades: mundialização, globalização, planetarização - novos desafios. Petrópolis: Vozes, 1996.

FAZENDA, I. C. A. Integração e interdisciplinaridade no ensino brasileiro - efetividade ou ideologia. São Paulo: Loyola, 1996. Coleção Realidade Educacional.

FÓRUM DE PRÓ-REITORES DE GRADUAÇÃO DAS UNIVERSIDADES BRASILEIRAS - FORGRAD. Política nacional de graduação. Manaus: 16-19 de maio 2004.

FORUM DE DIRETORES DE FACULDADES DE EDUCAÇÃO FORUMDIR. Diretrizes Curriculares para o Curso de Pedagogia - proposta do FORUMDIR. Disponível em < http://wwww. faced.ufba.br/rascunho_digital/textos:343. htm> On line. Acessado em 04/08/2004.

LEI DE DIRETRIZES E BASES DA EDUCAÇÃO NACIONAL No 9.394 de 15 de maio de 1996. Brasília. MEC, 1996.

MORENO, E.(org.) Da cidade virtual à cidade de pedra: contribuição para o debate do nosso futuro habitat. Trad. Beth Saad. São Paulo: Agência Estado, 1996.

SANTOS, B. S. Pela mão de Alice: o social e o político na pós modernidade. 3.ed. São Paulo: Cortez, 1996.

SAVIANI, D. Pedagogia: o espaço da educação na Universidade. In: Cadernos de Pesquisa. Campinas: UNICAMP, v.377, n.130, p. 99-134. Jan./abr.2007. 